\title{
Technologies of Seeing the Past: The Curzon Memories App
}

\author{
Charlotte Crofts \\ Department of Screen, Media and Journalism \\ University of the West of England \\ Bristol, BS16 1QY \\ charlotte.crofts@uwe.ac.uk
}

\begin{abstract}
This paper presents a practice research project based at The Curzon Community Cinema, Clevedon, UK. Working closely with the cinema to develop a locative or context-aware heritage application for the iPhone, the project aims to enhance the Curzon's new Heritage Lottery Funded exhibition, enabling visitors to gain further insight into the building, projection equipment and the history of cinema itself. The paper discusses the iterative design process, evaluates the first iteration and outlines plans for the next iteration, when the project will attempt to move seamlessly from the exterior of the building to inside the cinema.
\end{abstract}

Mobile applications. Heritage interpretation. Screen heritage. Content development. Digital memories.

\section{INTRODUCTION}

The Curzon Community Cinema, Clevedon is a unique heritage site. Not only is it one of the oldest, purpose-built, continuously operating cinemas in the world, and a listed building, it is also a fully functioning and operational cinema. It is home of the Curzon Collection of heritage cinema technology, whilst at the same time employing upto-the-minute cinema equipment in its every day operation, with the latest Dolby surround sound and, as part of the UK Film Council's Digital Screen Network, a state-of-the-art high-end digital projector. In 2010, the cinema received Heritage Lottery Funding (HLF) for structural repairs and to open up the building and collection to the public as a 'Living History Exhibition'. As a site for researching locative technology and cinema heritage, the cinema offers an incredibly rich context in which to explore how new media can be used to illuminate the history of moving image technology and the material culture of cinemagoing. In this introduction I will outline my key research objectives and questions and give an overview of the project's theoretical, political, artistic and historical contexts and methodologies. I will then go on to describe the first iteration, reflect on the evaluation and outline plans for the next iteration in the main body of the paper.

\subsection{Key research objectives}

As a filmmaker, and lecturer in film studies and video production, new to the field of experience design and locative media, one of my initial research objectives was to learn, through creative practice, how to be a creative producer of this new medium. The key research objectives, then, are both ambitious and pragmatic:

- To create a small-scale pilot that explores, through critical practice, how locative media could be used to enhance public understanding of the built-environment and physical apparatus of the moving image.

- Innovation in the creative application of positioning technologies in a heritage context, paying specific attention to the problem of indoor localization.

- To inform policy in the UK screen heritage and explore wider heritage applications.

\subsection{Theoretical, political and artistic contexts}

My thinking about locative media as a means of exploring screen heritage is informed by the "apparatus theorists"' of the 1970s (Baudry, Comolli, Heath, Metz, Mulvey, Wollen, all collected in Philip Rosen's seminal collection Narrative, Apparatus, Ideology: A Film Reader, 1972), who were interested in the cinematic apparatus both in terms of the equipment of production and projection and in terms of the conditions of spectatorship (the engaged spectator in a darkened communal auditorium). At the project's heart is a concern with both the culture and technologies of seeing: how we might use new screen media as a lens through which to understand the old cinematic apparatus 
and in turn historicise the new media. The idea is to use locative media to add depth to the everyday architecture of the cinema beyond that which is immediately apparent, and so enhance visitors' experience and understanding of the cinema and the collection. In this sense, the project is centrally concerned with the interface between cultural memory and the technological imaginary of the moving image.

Much attention has been given to UK screen heritage in the digital age. For example, the BFl's policy and strategy consultation document commissioned by the DCMS states "the public is entitled to access, learn about and enjoy its rich screen heritage wherever they live and wherever the materials are held" (Kelly 2007: 18). However, most of this document is directed to the digital restoration of, and online access to, filmic texts, rather than looking at the wider cinematic experience, the built environment, cinema technologies and other physical ephemera. Whilst digital access and film preservation are important, it is only one aspect of screen heritage and it is equally important to preserve, interpret and make accessible the technologies and physical spaces of cinema in order to understand cinema's cultural significance. Yet, in the UK, government policy has ignored this aspect of cinema culture, with the "temporary" closure of the NFT Museum of the Moving Image, London in 1999 becoming permanent, replaced by the BFI Southbank's Mediatech, a free digital film archive. In contrast, the Museum of the Moving Image (MOMI) in New York has recently had a $\$ 65$ million cash injection to expand their building, including a new gallery devoted to stimulating, and cutting-edge exhibits, many of which will be devoted to digital interactive art.

There is a growing movement to reclaim the position of the material object in the archive in the UK. For example, the UK Screen Heritage Network (not to be confused with the BFI's UK Film Heritage Group) has conducted a national survey of screen heritage artefacts and created the first online database of moving image objects, funded by the Museums, Libraries and Archives Council Renaissance Fund. Everyone's Virtual Exhibition (EVE) at The Bill Douglas Centre, Exeter allows users to curate their own virtual exhibition; MOMI, New York is developing CollectionSpace, an opensource web-based information system. Indeed, The Curzon's own website includes a virtual tour of still images of the collection. However, whilst it is important to enable digital access to physical artefacts, these archive projects remain confined to a virtual environment.

What is different and distinctive about my project is that it aims to use digital culture to enhance the public's relationship with the physical, material world of the cinema and its history by encouraging them to actually visit the site and experience it anew through creative media technologies. Where I am breaking new ground is in challenging the current UK government policy of using digital technology simply as a means of digitising objects and putting them on the web. In contrast, I am thinking about heritage in terms of material experience, not just digital archive. Whilst the specific focus of this project is cinema heritage, the intention is that the research innovations could also be applied to other forms of public heritage, museums, galleries and archives, particularly those dealing with material objects and the built environment.

Indeed, there is clearly both a consumer and an academic market for 'Digital Heritage' in the UK, and beyond, what with the Arts and Humanities Research Council's 'Digital Transformations in Arts and Humanities' theme and the numerous 'heritage apps' which are sprouting up, such as Heritage App (heritage-app.com), a geo-sensitive database of UK heritage sites triggered by GPS, and Fotopedia Heritage (fotopedia.com), which uses the infrastructure of Wikipedia to enable users to upload their photos of world heritage sites, linked to information on UNESCO's website. Internationally, there is work on such diverse heritage sites as the Shrine of Remembrance in Melbourne (DarienSmith et al. 2010), the Oakland Cemetery in Atlanta (Dow et al. 2005) and an historic guide to Venice (Epstein \& Vergani 2006).

There are a number of local locative media artists and projects that inform my work, some of which have a specifically heritage application, such as Hewlett Packard Labs' Extended Theatre Experience working with Watershed and Bristol Old Vic; Jackie Calderwood's e-merge project for Birds Eye View Film Festival; Zoe Irvine's Moulinex project (in collaboration with Arnolfini and Mobile Bristol); Blast Theory's Rider Spoke cycling theatre project; Tom Bennett's Interactive Places; Duncan Speakman's SubtleMob, working with mobile technologies to create live performance art. Aardman and the Museum of Bristol are exploring mobile technologies, virtual mapping and social gaming to create new media narratives.

\subsection{Historical context}

As the cinema's heritage is so integral to both the project's research objectives and the content of the App, it is necessary to outline some of the key moments in the cinema's history. The first cinema, The Picture House, was built in 1912 by James Newton Cox and his son, Victor, who had already been projecting pictures locally since 1910 with the Clevedon Cinephone Company (Thornton 2005: 6). 
The cinema was expanded in 1913 and, capitalising on its success, another cinema was built directly on top of the original building in 19212 , whilst the original cinema continued to operate, never missing a screening (Thornton 2005: 23). After World War II the cinema was renamed The Maxime, in 1945, and subsequently The Curzon, in 1956. The cinema was saved from closure by the community in 1996 when a charitable trust was created to manage the cinema under the auspices of manager Jon Webber. Apart from a few key salaried staff, including the new manager Gareth Negus and the Education Officer Cathy Poole, much of the cinema's activity is undertaken on a voluntary basis, from duty managers, projectionists, ushers and guides up to and including the dedicated board of trustees.

My interest in the cinema began when I interviewed Weber, about their receipt of one of the UKFC Digital Screen Network projectors in 2006, as part of a HEFCE-funded research project on the impact of digital technology on the feature film industry. I later filmed at the Curzon on the $10^{\text {th }}$ anniversary of the Community Cinema, when they had an open house and allowed public access to the Curzon Collection. I was shown around by passionate and knowledgeable volunteers and became hooked on The Curzon and the history of cinema. As mentioned above, the Curzon Collection is unique in being housed within such an historic building. The context of the collection offers an exceptional opportunity to explore both the technologies of cinema and the cultural practices of cinema-going in one place.

\subsection{Methodologies}

\subsubsection{Self-reflexive practice-led research}

Throughout the process, I have been reflecting critically on the theoretical underpinnings of my practice via an ongoing research blog (curzonproject.wordpress.com). I began my journey from filmmaker to creative producer at the Pervasive Media Summer School (July 2010), run by the Digital Cultures Research Centre at the Pervasive Media Studio in Bristol. This has informed my practice with a shift from the traditional linear workflow of film production, to a more cyclical and iterative design process (see section 1.4.4). Scoping and designing the pilot within tight parameters that are manageable and deliverable within the limited budget and timescale is challenging, as is the need to construct a compelling experience around the location of the building whilst also attempting to do justice to its rich and often very personal history. Compelling content, then, is integral to the experience and requires a great deal of planning, testing, reflection and refining, to ensure that the interface between user, location and technology is satisfying.

\subsubsection{Researching the Curzon and its Collection} My research into the history of The Cuzon draws on curator of the Curzon Collection, Maurice Thornton's book The Everlasting Picture House (2005), an invaluable source of historic moments to map over the physical space. The cinema won HLF funding to "increase access to the building and its history .... giving an insight into the cinema's past" (Screen Talk, Autumn 2010: 2), with the aim to "enhance public access, experience and understanding of the cinema building and the Curzon Collection, that together demonstrate the living history of cinema from the early 20th century to the present" (Screen Talk, Summer 2010: 1). This has enabled this project to contribute in a number of ways to the cinema's development strategy, including working closely with the Education Officer, Cathy Poole, to collect digital video memories for the HFL funded Curzon Memories Project (lending its title to the App). Together we have been gathering oral histories, including Muriel Williams who was in the building when it was bombed in 1941 (see figure 4, below), Lady Julia Elton, daughter of Sir Arthur Elton a key filmmaker in the 1930s GPO Documentary Film Unit, Kathleen and George Dimond, who worked as a maid for Blanche Cox and as a "button boy" in The Picture House in the 1930s, respectively. These digital video memories build on the work of Cathy McKerras who has been collecting audio memories.

\subsubsection{Technical research \& development}

The App is being developed with partners from local technology companies, Jo Reid (Calvium) and Tarim (Media Playgrounds), using the Calvium Player. Reid was instrumental in developing Hewlett Packard's MScape platform (see http://www.mscapers.com), used for many of the early locative media projects based in Bristol (see Blythe, Reid, Wright and Geelhoed, 2006 and Reid, 2010). Although designed for HP's iPAQ, a pocketsized handheld navigator, using Global Positioning System (GPS) tracking technology to run locationbased programs, MScape could function on any GPS-enabled device running Microsoft Windows Mobile. Conversely, a current frustration is that the current project is being developed for a proprietary mobile phone, the iPhone. Therefore future thought will go into making it more generally accessible. Currently GPS technology only has an accuracy of $10 \mathrm{~m}$ and, it is already clear from the first iteration, that this creates issues (a point I shall return to later). Also, GPS cannot be used for interior locations, so the main mechanism for triggering content indoors will be QR code (2-D barcodes).

\subsubsection{Iterative design process and user experience evaluation}

Proof of concept prototyping and an iterative design process are used following Reid's "Experience 
Design Framework" (2010). As Reid asserts, "emulation on the PC is not sufficient, it is really important to try things out in the environment" and it is therefore necessary to "develop, test and refine" the project phases, looking at core mechanics, usability and enjoyability (ibid). There are two phases to the project, the first iteration involved a prototype locative tour of the exterior of the building in the form of a downloadable iPhone application that uses GPS to trigger context-aware images and audio recordings according to where the user is positioned in relation to the cinema. Digital memories, voiceover narration and dramatisation are combined to bring the history of the building and the community to life. At time of writing I am in a position to reflect on the first iteration, which uses scratch content to explore the interface and this is what will form the basis of the following discussion and inform the development of the next iteration.

\section{THE FIRST ITERATION}

\subsection{Overview of the first iteration}

On downloading the App from the Calvium Player, the visitor is greeted by a pair of closed cinema curtains and nostalgic organ music. The tabs pull back and reveal the cinema screen and the title card 'Welcome to the Curzon Memories App' appears, with the word 'Admission' and a pointing hand, which is a button to move to the next screen (see figure 1).

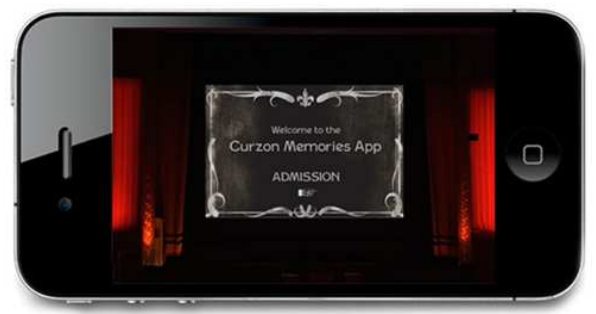

Figure 1: Curtains open onto the welcome screen

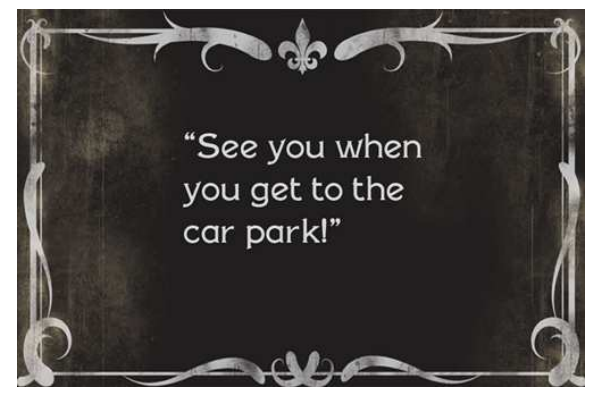

Figure 2: Silent movie title card

The aesthetic design principles for the interface are tied to the cinematic, with specific reference to the silent screen: the use of the widescreen or landscape orientation of the iPhone, the movie of the cinema tabs opening on download, the organ music, the predominance of the colour red, the conceit of the cinema screen as the main interface for text and images (see figure 1). Using silent movie title cards to give instructions, the following two screens give information on how to get to the Curzon and car parking, using the pointing hand icon to navigate to the next screen (see figure 2). A map then appears with the instruction 'Make your way to the Curzon car park to start' - there are a number of nearby car parks in Morrisons, Lidl and the North Somerset Council free car park which were grouped into one big 'Car Park' zone. A "No 3G Map" option takes you to a map image with overlaid buttons so that you can at least experience the first audio clip in each region even if the GPS is problematic.

When you arrive at one of the car parks, the GPS picks up your location and activates a title screen asking users to tap the hand when you are ready to start'. As you tap the screen and walk towards the Curzon, you hear two voices, one male and one female, discussing the birth of the cinema. The male voice comments on the present: "Look at them all with their shopping bags, we should have built a supermarket the amount they spend in a week. We missed a trick there, Mama" - referring to contemporary shoppers. The female voice disagrees, "No, no, no, Darling, the magic of the moving pictures, it brought this town to life, the music, the stars, the glamour, Clevedon needed a cinema". These are dramatisations of real people: Victor Cox, and his stepmother Blanche Cox (nee Harwood), pictured below in figure 3 .

The aim was to have a mix of male and female narrative voices representing the two oppositional formations of cinema, the hard-nosed business end (represented by Victor Cox, the son of James Newton Cox, with whom he set up the cinema) and "the magic of the moving pictures" (represented by Blanche, an operatic diva said to have travelled the stages of Europe before marrying Cox Senior). Victor and Blanche became very close and she remained with him until her death (Thornton 2005: $5)$.

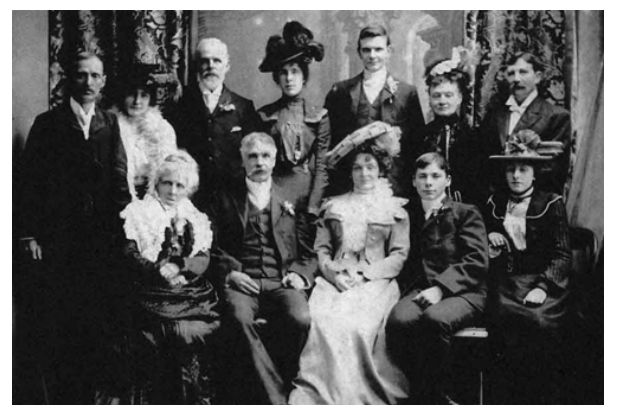

Figure 3: The Cox's wedding

As we move to the next zone (the Mews), an oral memory from Kathleen and George Dimond is triggered, describing Victor Cox as "the meanest 
man in Clevedon ... tighter than the paper on the wall" whereas Blanche is a cast in a more positive light as a "generous woman." This plays over the wedding photo pictured in figure 3 , with James Newton Cox (second from left, front row), Blanche Harwood (centre), and the young Victor Cox (to her right).

Dramatised historical figures, fictional characters (school children going to the Saturday matinee) and oral memories (gathered for the HLF supported 'Curzon Memories Project'), intertwine to create a complex and often contested history of the cinema. The Dimond's version of Cox, is a point in case, because Victor Cox is also known to have been a significant benefactor to Clevedon (Thornton 2005: 79). As we enter into each zone, the GPS triggers a series of audio clips supported by images on the cinema screen. The App is designed so that there is a base layer of audio triggered on entering each region. If users linger in an area, more clips play allowing the visitor to delve deeper into the cinema's history. If you linger in the Mews zone you hear Rita Gregory relating an anecdote about how Mr Cox was inspired to build a cinema by seeing her uncle Jack playing with a home-made magic lantern set.

In 'The Stable' zone we hear Victor Cox reminiscing: "this was all fields", referring to fly taxi operator Albert Type keeping horses here (cue soundtrack of horse and cart), and a located reference to the cinema "still using the stables". This is over the image of the eastern wall of the cinema before Great Western Road was built. Blanche recalls Victor and his father's vision to build a "respectable picture house... no more projecting in the town hall". In 'The Paddock' zone Victor Cox announces the opening of the first cinema, explaining that the proceeds will go to victims of the Titanic disaster - over an image of the opening matinee flyer, a projector whirrs into life. Victor remembers the naysayers when the cinema was first proposed: "They thought we were mad, but I knew the future was in the cinematograph"... and Blanche wonders how they ever made do in that "tiny cinema" before the present building was constructed.

At the North Eastern corner of the building, Victor says "it doesn't look like much from this angle" and Blanche goes on to list the amenities of the Oak Room Café, followed by two very different oral memories of the café. Along Old Church Road, the front of the building, the mix of dramatised narrators and oral memories continues, in tandem with sound effects: a crowd of excited children waiting for the Saturday Matinee, over memories of childhood trips to the Curzon. Victor admires his handiwork, stating that he's "still proud of the design of that building" and Blanche reminisces about the day they hired charabancs to take the workers on a picnic to Cheddar Gorge.

At the front door, the audio walk climaxes with the story of a bomb going off outside the cinema in 1941, resulting in Clevedon's one and only causality from a direct hit (Thornton 2005: 54). The blast shattered the luminette window, which has never been replaced. This is related primarily through the memory of Muriel Williams who was in the building on the night, supported by a soundscape of grumbling German bombers, air raid sirens, and shattering glass. Kathleen Dimond then reflects on the shrapnel damage still visible above where the blown out window used to be (see figure 4). The first iteration ends with the voices of Victor and Blanche reflecting on how remarkable it is that "the building is still flourishing after all these years".

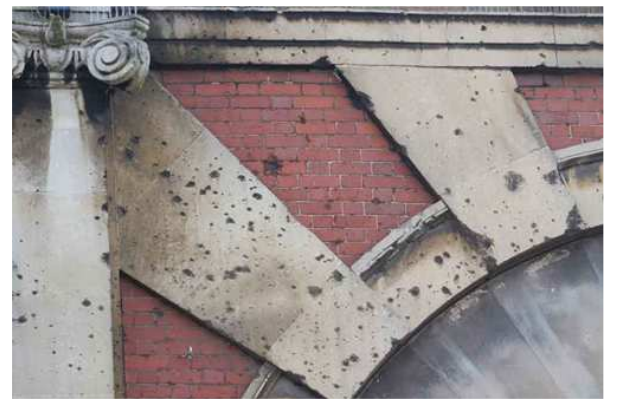

Figure 4: Detail of shrapnel damage from WWII bomb, which exploded outside the Curzon, 4 Jan 1941

\subsection{The test and evaluation process}

The first iteration was tested in early March 2011 led by colleagues, Jon Dovey and Constance Fleuriot, as part of their Pervasive Media Knowledge Transfer Fellowship project. Participants were invited to write down how they would describe the App in a listings magazine, followed by a focus group discussion about the experience. Nine participants took part in the test, drawn from the Curzon, Pervasive Media Studio and UWE and seven took part in the focus group discussion. The aim was not a detailed evaluation of 'user experience' at this stage (which will follow in the second iteration), but just to get a feeling for how the application was beginning to work, what issues were raised and how well initial plans were being realised (following Reid 2010, 2011).

The App was experienced primarily as a 'history walk', with 'cinema', 'memories', 'stories', 'pictures', 'sound', 'tour' and 'place', 'tour' and 'App' featuring strongly in descriptions. The 'climatic' moment of the WWII bomb was mentioned in two of the seven descriptions. The location was also alluded to: "you hear different parts of the history near the places that they happened". Seth Giddings, a UWE colleague who documented the test and took 
part in the focus group, suggested "from the viewpoint of an observer watching the players and phones, not the App itself, this is an activity that includes accessing, negotiating and to a certain extent, understanding GPS signals, the relative strengths of different phone providers, and a willingness to relate bodily position (through walking) to initiating the App itself and triggering its stages".

\subsection{Strengths and weaknesses}

The most resonant moments were highlighted as those in which the audio soundscape complimented the memories and interacted with what was being said. For example, Albert Type's horse and cart, the charabanc driving off and the bomb explosion. Other compelling moments were when the voices from the past made explicit links with the present:

\begin{abstract}
I liked the bit at the very beginning when you have the character talking about all these people with their shopping bags, because you've got two huge supermarkets, there are people with their shopping bags, and those little things to get people started, I thought was nice. (Focus group discussion)
\end{abstract}

And it was felt by another participant that more "locative" moments like this could be designed into the next iteration:

\begin{abstract}
I was very struck by how much more work you should do in the script to actually relate the present busy, windy, cold, narrow corner to the sense of historical expanse and the fields. I think the thing we did with shopping bags at the beginning was good, but I think actually there's a lot more of that relating to where you actually are in the present. (Focus group discussion)
\end{abstract}

The brevity of the audio tracks and therefore the length and depth of the experience was highlighted in the 'listings' exercise: "a short stroll down memory lane", "a little tour of the cinema's history", "snippets". The audio tracks were deliberately brief to facilitate visitors engaging in more open exploration and reduced waiting times. With hindsight, there actually needs to be more layering of audio (if not longer sound clips), which can be triggered should the participant want to linger in the same place for longer. GPS was raised as a key issue in the test, highlighting that the App needs to be developed to continue when the GPS signal is unreliable, which happened at the beginning of the test. Two suggestions arose: to create a linear walk with minimal GPS (to acknowledge they've arrived in the car park), which would be easily adaptable to non-GPS enabled devices. Alternatively, to create a more non-linear walk and work harder to connect location and content to zones that can be accessed in any order. The experience is currently designed to start in the Car Park 'zone' and the opening instructions are aimed at someone coming from outside Clevedon. The next iteration should also address local users, who may walk to the cinema from the North West or East and start from the front door of the Curzon. There could be an "I'm already at the Curzon" option and the zones need to be navigable in any order. Another issue with GPS is the need to make the application accessible to a wider audience and, in turn, within the budget of the Curzon to purchase a demonstration model. Tom Bennett, Interactive Places, has designed his latest iPhone App on the Bristol Blitz to be "browsable" on the non-GPS enabled iPod Touch and iPad, as well as working as a GPS walking audio tour of Bristol (interactiveplaces.co.uk).

There was consensus about the need to be led more in terms of the geography of the building, and its history, through both the audio and the visuals. For example, if you've never been before then it was really difficult to know where the Curzon was in relation to the car park, and at points participants would have liked more guidance about who they were listening to and what they should be looking at:

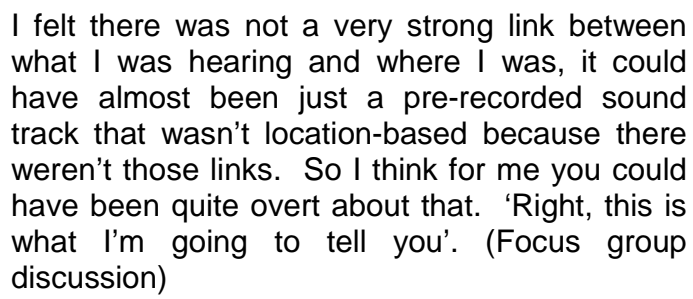

Another issue that was highlighted by actually testing the App in situ was the lack of space on the pavements surrounding the Curzon and the difficulty of seeing the building at such close quarters (see figure 5 as opposed to figure 4).

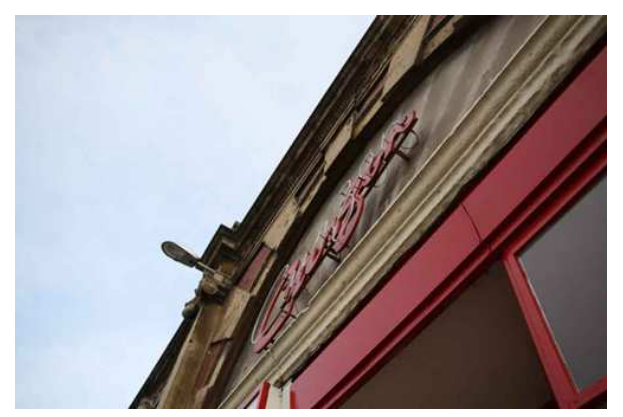

Figure 5: The front entrance of the Curzon, demonstrating the difficulty of seeing the façade from the pavement

One participant enjoyed the "bit with shrapnel damage on the building", but felt that she could have viewed it from a better vantage point: "because it's such a narrow space in front of it, you need to cross the road to get that view of it. [...] 
But I think if I'd been told to go and stand in that lane opposite and look back, then that would have worked really well", which brings up the issue of road safety.

In terms of aesthetics, the size of the images and text when using the conceit of the cinema screenwithin-a-screen created problems. It was far too small (see figure 1) and, although this was anticipated with a tap to zoom feature, this was not clearly signposted to the user, making the interface frustrating to use. Another concern was the relationship between fact and fiction, the combination of the dramatisation of real characters (Victor and Blanche), plus oral history and reconstructed soundscapes. However, while few of the participants recognised the voices (and some felt more comfortable with this than others), they felt able to differentiate between the dramatisations and the oral histories. Another problem highlighted in the discussion was that some basic factual information about the history of the building didn't come across.

\section{PLANS FOR THE SECOND ITERATION}

\subsection{Responding to feedback}

A key finding from the first iteration was the need for more explicit user guidance in order to locate the experience, and to reveal the dense history relatively quickly without becoming didactic. The Curzon's 'Living History Exhibition' has an audio commentary voiced by Tony Robinson, which already does this. I want to leave room for the user's imagination, but not leave them in a state of confusion. To this end the idea of creating a fictional character emerged, one that could guide and introduce you to the other characters and point you in the right direction - as suggested in the focus group: what better figure than the Usherette? The Usherette will fulfil a dual function: historic and geographical guide, leading visitors historically and in terms of specific locations or angles of viewing. She can suggest that you cross the road and remind you to be careful, and introduce Victor Cox and his stepmother so that when you hear their voices, there is enough context for it to have meaning. She can direct your gaze and describe things that are no longer there. Importantly, she can be the link between outside and inside, giving a sense of continuity as the application moves indoors, and offer reassurance and support for those unfamiliar with the QR Code interface, the primary mode of triggering audio inside the building.

Alongside the Usherette, visual strategies will be used to aid the navigation of space. Below (figure 6 ) is a mock-up of a very literal example, using the hand that appears as the navigation on the title cards. This technique could be used to orientate the unfamiliar visitor, or to situate them in a specific spot, such as Darin-Smith et al.'s "suggested viewing points" (2010: 340).

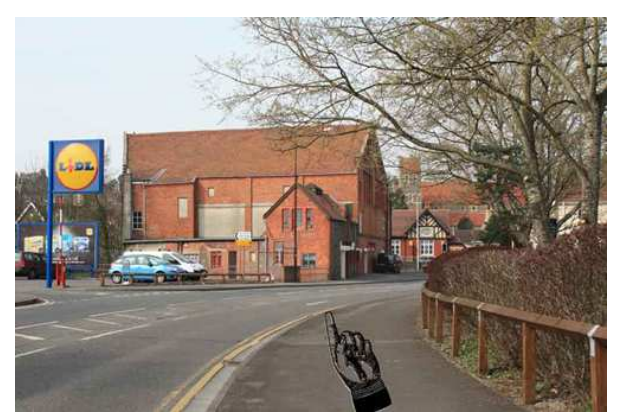

Figure 6: The approach from Morrisons car park, with hand pointing in the direction of the cinema

The next iteration will lead visitors by using the cinematic technique of the close-up, guiding them to specific details. As Darin-Smith et al. established in their Shrine of Remembrance guide:

one of the most engaging techniques deployed in the guide appeared to be the technique of directed-looking [...] The replication of present objects in images was accepted by many as a useful device to direct closer inspection [...] Like a magnifying glass the guide provided enhanced seeing of what was there. (2010: 353)

This technique will be used to invite an archaeological gaze, so that they notice the last traces of lettering on the brickwork (figure 7), and the architectural clash of Classical and 1920s stone masonry (see figure 4).

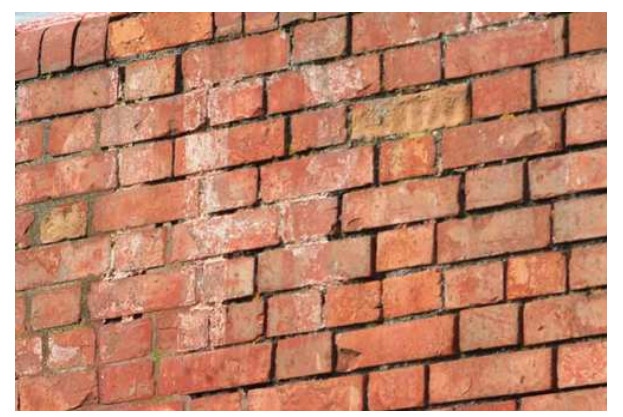

Figure 7: Eroding paintwork -you can just make out the letter ' $R$ ' of 'Picture House'

Another visual strategy to link between present and past is the use of simple augmented reality (AR), overlaying images from then and now (see figure 8), without the need for high-technology:

what I always say is take a picture of now and a picture of then [,,,] and don't do anything clever with gyroscopes, GPS positioning. I think crude $A R$, in the sense that, hold the phone up when it's lined up with what's there, press the button. (Focus group discussion) 


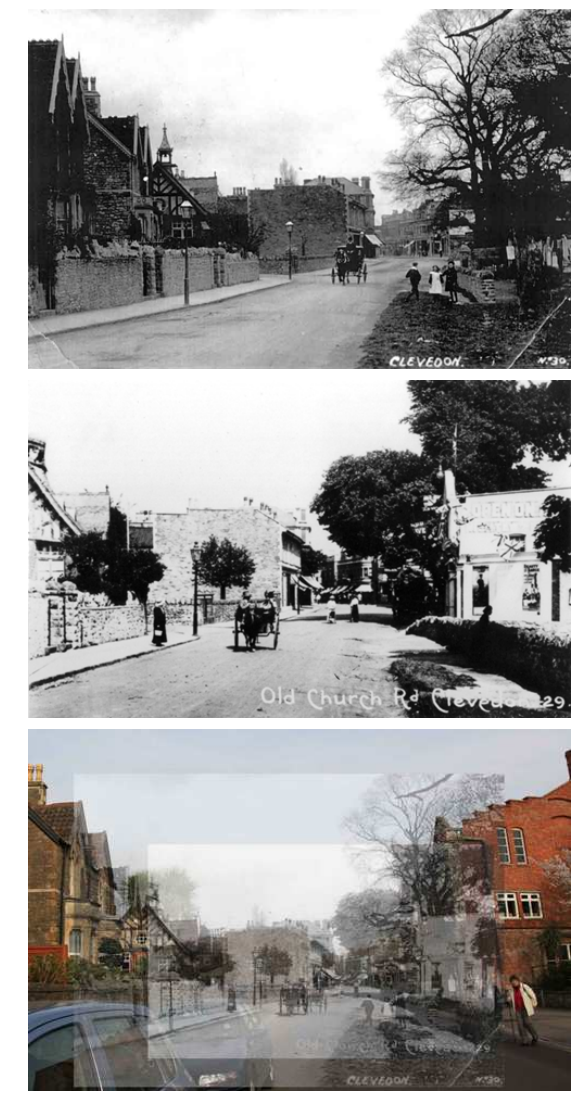

Figure 8: Old Church Road, pre-1912 (top), post-1912 with the first cinema on the right (middle) and both images superimposed over the extant 1921/22 building

\subsection{Evaluating the second iteration}

The second iteration will be tested by the Youth Panel and volunteers at The Curzon in May. I will use a mixture of structured interviews concerning the research objectives, open questions and a feedback questionnaire to get both quantative and qualitative feedback from users to ascertain how they experience the archive through the new technology and how this differs from their experience of traditional exhibits (Reid 2010, 2011). The results of the evaluation will feed back into the design process, for the third and final iteration, as well as forming the raw data for further reflection and dissemination.

\section{ACKNOWLEDGEMENTS}

This research is supported by the Digital Cultures Research Centre and an Early Career Starter Research Grant from the University of the West of England. Thanks are due to Jo Reid at Calvium, Tarim at Media Playground, Professor Jon Dovey, Constance Fleuriot, Sam Kinsley, Patrick Crogan, Seth Giddings and Nick Triggs at DCRC for mentorship, support and help with the evaluation; and also to Gareth Negus, Cathy Poole, Maurice Thornton and the Board of Trustees at the Curzon Community Cinema, Clevedon as well as all the contributors to the Heritage Lottery Funded Curzon Memories project.

\section{REFERENCES}

Blythe, M., Reid, J., Wright, P. and Geelhoed, E. (2006) Interdisciplinary Criticism: Analysing the Experience of Riot! A Location Sensitive Digital Narrative. Behaviour and Information Technology, 25(2), pp. 127-139.

Darian-Smith, K., Lewi, H., Pearce, P. and Smith, W. (2010) Re-connecting visual content to place in a mobile guide for the Shrine of Remembrance. Electronic and Visual Arts (EVA 2010).

Dow, S., Lee, J., Oezbek, C., Maclntyre, B. Bolter, J. and Grandy, M. (2005) Exploring Spatial Narratives and Mixed Reality Experiences in Oakland Cemetery. ACE2005, pp. 51-60.

Epstein, M. and Vergani, S. (2006) History Unwired: Mobile Narrative in Historic Cities in A. Celenano (ed.). Proceedings of the Advanced Visual Interfaces Conference, Venezia, Italy, pp. 302-305.

Kelly, R. (ed.). (2007) Strategy for UK Screen Heritage. BFI: London.

Rosen, P. (1972) Narrative, Apparatus, Ideology: A Film Theory Reader. Columbia University pres: New York.

Reid J., Hull R., Clayton B., Melamed T. and Stenton P. (2011) A research methodology for evaluating location aware experiences, Personal and Ubiquitous Computing 15: pp. 53-60.

Reid, J. (2010) Evaluation Methods Within Pervasive Media. Pervasive Media Summer School, Bristol, July 2010. (PowerPoint Presentation).

Thornton, M. (2005) The Everlasting Picture Show: The Story of Cinema in Clevedon and Portishead. Curzon-Clevedon Community Centre for the Arts, Clevedon.

Vlahakis, V., Karigiannis, J., Tsotros, M. Gounaris, M., Almedia, L., Stricker, D., Gleue, T., Christou, I., Renzo, C. and loannidis, N. (2001) ARCHEOGUIDE: First Results of an Augmented Reality, Mobile Computing Systems in Cultural Heritage sites. In Proceedings of VAST'01, pp. 131-40.

Screen Talk (Summer and Autumn, 2010), www.curzon.org.uk (28 April 2011). 